\title{
WUJUD DAN EMANASI DALAM PANDANGAN IBNU ARABI
}

\author{
Oleh \\ Zulkifli \\ UNIVERSITAS ISLAM NEGERI RADEN INTAN LAMPUNG \\ zulkifli.b62@gmail.com
}

\begin{abstract}
Al-Farabi decribes the sequences of ovents that may be a form of (natural beings) of substances that must be al-being (God). He asked that God is a mind that is not a thing. Evrything emanates (emanation) of god, becouse god knows (think) his substance and who knew that he was the cause of all his known form. Then the non-physical beings that there is absolute a lot, so that the amount can be rated in a hierarchy, culminating in a god. How does it happen emansi, Farabi explains that God is really the One at all. Becouse he came out of him as well of one form only. When he came out off the form of God who spelled, it means, it's god spelled substance.
\end{abstract}

Key words : Wujud,Emanasi, Filsafat dan Ibnu Arabi 


\section{A. PENDAHULUAN}

Nama lengkap al-Farabi, Sadalah Abu Nasr, Muhammad, Ibnu Muhammad, Ibnu Trakhan, Ibnu Uzlaq, Al-Farabi. Dalam lapangan kebudayaan islam, terkenal dengan Abu Nashr Bapa Nasr', yaitu nama putranya sebagai juga Ibnu Sina, lebih terkenal dengan nama Abu Asli. Ia bukan berasal dari Arab, akan tetapi seseorang keturunan turki. Dlahirkan di kota farab (Kampung Utara) sekarang menjadi bagian Republik Uzbekistan, Rusia ${ }^{2}$. ayahnya adalah seorang iran dengan seorang wanita turkestan ${ }^{3}$ pada tahun 330 H/941 M. Ia pindah ke Damsyik, kemudian menetap di kota ini sampai usianya 80 tahun dan wafat dalam tahun $339 \mathrm{H}$ atau $950 \mathrm{M}^{4}$.

Sejak kecil, al-Farabi suka belajar dan ia menguasai bahasa-bahasa Iran, Turkestan, dan Kurdistan. Setelah besar ia meninggalkan negrinya menuju Baghdad sebagai pusat pemerintahan dan ilmu pengetahuannya pada masanya. Dan selamanya ia disana menghabiskan waktunya untuk belajarilmu logika, kemudian pindah ke Haran sebagai salah satu pusat kebudayaan yunani di Asia kecil untuk berguru pada Yuhana bin Jilan. Tetapi tidak lama kemudian ia meninggalkan kota itu dan kembali ke Baghdad selama 30 tahun untuk mendalami ilmu tentang filsafat.

Al-Kindi meletakan dasar-dasar filsafat islam, kemudian datang zaman berikutnya Abu Nasr al-Farabi. Ia memperkokoh dan memantapkan dasardasar yang telah di letakan oleh al-Kindi. Sehingga al-Farabi dinamakan guru ke dua (al-mu'allimuts-tsani) karena Aristoteles di pandang sebagai guru pertama ${ }^{5}$. dalam buku-buku filsafat islam, Aristoteles itu tidak bisa disebutkan namanya secara langsung, akan tetap di panggil dengan nama guru. Setelah filsafat Al-Farabi berkembang, Aristoteles dipanggil dengan nama guru pertama, dan Al-Farabi disebut dengan gelar guru kedua.

Perkataan pertama dan kedua ini, tidak sama dengan pengertian kelas sekolah. Setelah aristoteles tidak ada lagi dan ilmunya telah disalin oleh Al-Farabi, maka tugas aristoteles dalam lapangan filsafat ini sudah habis. Yang menyambung tugas ini adalah Ai-Farabi, bukan dari aristioteles lagi. Hal ini akan diterangkan kemudian.

\footnotetext{
1Oemar Amin Hoesin. Filsafat Islam, Bulan Bintang. Jakarta, 1975, hal

2 Thawil Akhyar Dasoeki, sebuah komplikasi Filsafat Islam, Dina Utama, Semarang,1993,hal 26
}

${ }^{3}$ Ahmad Hanafi,MA, pengantar Filsafat Islam, Bulan Bintang. Jakarta, 1990, hal 81

${ }^{4}$ Ibid.

${ }^{5}$ Ahmad Fuad Al-Ahlawi, Filsafat islam. Pustaka Firdaus, Jakarta, 1997, hal.73 
Keterangan pertama, pada umumnya, diterima oleh sebagian besar para sarjana, ialah Al-Farabi telah memberikan pada filsafat islam, sebuah teori logika, telah disalin dalam bahasa arab. Yang terpenting diantaranya adalah buku-bukunya yang bernamaCategories, Hermeneutics, First Analitics, Sekon Analitics, yang semua itu di bubuhi dengan komentarkomentar yang diperlukan.

Ahli-ahli filsafat islam memberikan gelaran guru kepada Al-Farabi, adalah jasanya dalam lapangan logika. Karena ilmu logikanya itu, ia dianggap failsuf tulen, parexcellence, murni. Tulisan-tulisan Al-Farabi dalam ilmu logika, sebagian telah hilang, ada sebagian lagi berupa naskah, belum lagi diterbitkan. Buku-bukunya yang sekarang terdapat idak dapat dijadikan untuk sebagai bahan menilai sampai kemana kebesaran AlFarabi dalam abad ini, sebagai seorang ahli logika. Penyelidikan ini masih terus dikerjakan, sambil mencari buku-buku Al-Farabi yang hilang.

Pada bagian Al-Kindi diatas, sudah kita katakan,bahwa Al-kindi mendapat serangan karena kelemahan nya dalam ilmu logika. Meskipun filsafatnya semakin baik, akan tetapi kekurangan nya dalam logika, ia tidak dapat mengatasi Al-Farabi. Al-Farabi telah membicarakan berbagai system logika, dan menunjukan bagian-bagian yang terpenting untuk membentuk fikiran, baik secara edukatif ataupun secara indukatif, sehingga dapat di fahamkan oleh pembaca-pembaca dalam bahasa arab. Kemampuan Al-Farabi dalam lapangan ini dinyatakan oleh Al-Kifti seorang ahli sejarah "al-farabi" telah memberi tafsiran kepada berbagai buku logika.

Diterangkannya, apa-apa yang tersembunyi didalamnya, dibukanya cadar-cadar yang selama ini menutup rahasianya, diolahnya sehingga lebih mudah, dipilihnya mana yang perlu, kemudian di tuliskannya dalam bukunya dengan susunan yang teratur, baik dan dengan gaya bahasa yang menarik.

Selanjutnya, karangan Al-Farabi dalam berbagai disiplin ilmu sampai saat ini banyak yang belumditerjemahkan, dan dalam pembahasan pada kesempatan ini kita akan membatasi masalah wujud dan dimensi, yang menjadi dasar pemikiran Al-Farabi pada masalah-masalah yang menjadi bahasanya.

\section{B. PEMBAHASAN}

Pengertian wujud menurut tauhid adalah ada,salah satu sifat allah yang wajib ada. Sedangkan wujudiyah,mempunyai dua makna yaitu, a'yah tsabibithah artinya zat yang tetap (Allah) dan 'ain kharijiyah artinya zat yang luar, kulit ${ }^{6}$. Sedangkan pengertian emanasi adalah teori untuk

${ }^{6}$ MuchtarEffendi,SE, Insiklopedi Agama dan Filsafat, Universitas Sriwijaya, 2001, hal. 429

Wujud dan emanasi dalam pandangan ibnu arabi 
menjelaskan bagaimana terciptanya alam semesta 7. Selanjutnya dalam insiklopedi tetamatik Dunia Islam menyatakan bahwa emanasi adalah teori untuk menjelaskan bagaimana terciptanya alam semesta ini ${ }^{8}$. Dengan demikian dapat kita simpulkan bahwa wujud dan emanasi adalah suatu teori tentang wajibul wujued (Tuhan) dan mumkinul wujud (Makhluk).

Mengenai ketuhanan Farabi jelas. Dengan menitiknya ia mencari pencipta dalam bidang metafisika,dan menetapkan perkara baru (hadist) dan perkara abadi (qadim). Ia berpendirian,bahwa seluruh yang ada (maujud) tidak terlepas dari keadaan,yaitu wajibul wujud atau mumkinul wujud. Tidak ada lain diluar dua perkara ini yang mumkinul wujud lahir dengan sebab. Sedangkan yang wajibul wujud sudah ada dengan tidak bersebab,ia memiliki zat yang agung dan sempurna,ia memiliki keagungan mencipta dalam keseluruhan sejak azali,berdiri sendiri,tidak berubah dari zaman ke zaman,baginya kembali dari seluruh akal,seluruh kewajiban,seluruh yang dapat dipikirkan dan yang memikirkannya,semuanya satu bagi-Nya kembali puncak segala kesempurnaan,segala keindahan,dan segala kecantikan,bagi-Nya kembali segala rahasia tidak dapat dijelaskan dengan bukti,karena ia sendiri merupakan bukti untuk seluruh alam,ia adalah sebab yang pertama bagi semua yang wujud dan ia sendiri yang dapat mengetahui intisari zat-Nya.

Wajibul wujud itu dengan segala keterangan tak dapat tidak hanya satu tunggal dan tidak ada yang sama dengan Dia. Jika ada yang sama sentuhlah bersama pula dalam segala zat dan sifatnya,dan hal itu tidak mungkin,karena tidak ada satu dalam zat-Nya. Wajibul wujub yang pertama,yang satu tunggal yang benar dan menunjukan segala sesuatu yang membatasi. Jika adamaanusia yang menyebut beberapa nama allah itu hanyalah sekedar menunjukan kepada zat-Nya tidak mengubah zatNya itu,kadang-kadang disebut dengan beberapa nama yang indah hanya untuk menyatakan kebesaran terhadap pencipta alam.

Al-Farabi menjelaskan urutan-urutan kejadian suatu wujud yang mungkin (alam makhluk) dan zat yang wajib al-wujud (Tuhan).Ia menanyakan bahwa tuhan adalah akal pikiran yang bukan berupa benda. Segala sesuatu memancar (emanasi) dari tuhan, karena tuhan mengetahui (memikirkan) zat-Nya dan yang mengetahui bahwa ia menjadi sebab bagi semua wujud yang diketahui-Nya. Maka wujud-wujud non fisik mutlak

7Ibid, hal. 110

${ }^{8}$ Dewan Editor, Insicklopedi Tematis Dunia Islam Pemikiran dan Peradaban, Icthiar Baru Van Hoeven, hal 20

${ }^{9}$ Osman Bakar, Classifikation Of Knowledge In Islam, Tj. Purwano, Mizan, Bandung, 1998, hal. 166 
yang ada ini banyak, sehingga jumlahnya dapat diperingkat diperingkat secara hierarkis,yang berpuncak pada tuhan 9 . Bagaimana cara emanasi itu terjadi, Farabi menjelaskan bahwa tuhan itu benar-benar Esa sama sekali. Karena itu ia keluar dari wujud Tuhan yang terbilang,maka berarti, zat tuhan itu terbilang.

Selanjutnya al-Farabi memberikan jalan untuk mencapai kesucian jiwa tidak hanya melalui jalur tubuh dan amal-amal badaniyah semata,tetapi secara primer dan secara esensial juga harus melalui jalur akal dan tindakan-tindakan pemikiran.

Ada berbagai keutamaan amalan badaniyah tetapi ia tidak berarti apa-apa disisi keutamaan rasional teoritis,walaupun perbuatan-perbuatan yang baik dan kerusakan yang terpuji merupakan bagian dari kebaikan, tetapi yang terbaik terdapat didalam masalah yang dikaji,dalam realitas yang kita singkapkan dan dalam ma'rifat yang mendidik jiwa yang menggigikan akal kita. Hal ini dikarenakan akal manusia, dalam merambah jalan peningkatan dan perkembangannya,melalui fase-fase yang satu sama salin menopang, karena pada awalnya ia merupakan akal potensi, tetapi kemudian jika telah mempersepsi sebagian besar pengetahuan yang umum dan realitas yang universal maka ia akan menjadi akal yang actual. Batas pandangannya meliputi mayoritas,maka ia meningkat menuju tahapan tertinggi yang bisa dicapai manusia,yaitu derajat akal mustafad (akal limpahan) atau derajat emanasi.

Dalam masalah kebahagiaan al-Farabi membahas bukan hanya teoritas tapi juga praktis. Bahkan ia berjuang agar dalam pemikirannya dan analisanya ia bisa sampai martabata emanasi san inspirasi,sebagaimana yang sebelumnya dilakukan oleh plotinus ${ }^{10}$. maka jelaslah bahwa untuk mencapai kebahagiaan jiwa manusia harus suci agar dapat menembus tabir-tabir ghaib, jiwa yang suci tidak membutuhkan wujud dalam eksistensinya kepada materi. Jadi ruh (jiwa) suci dapat melihat alam ghaib, mendengar sambutan dan melintasi indrawi menuju alam kesaksian yang hakiki dan keindahan yang abadi. Yang akhirnya dikenal dengan teori ittidah (bersatu) dan ittishol (berhubungan denga tuhannya) ${ }^{11}$. Membawa perbedaan yang jelas antara teori al-hulul versi alhallaj dengan teori kebahagiaan ala al-farabi. Karena kata pertama bias diarahkan kepada teori tasawuf yang menuju pada pelarutan sedangkan kata kedua diarahkan pada teori filosofis yang mengarah hubungan manusia dengan ruh semata.

${ }^{10}$ Ibrahim Madkour, Filsafat Islam Metode dan Penerapan nya, Grafindi Persida, Jakarta, 1993 hal.33

${ }^{11}$ Ibid, hal.40

${ }^{12}$ Dewan Editor, Loc. Cit, hal.20

Wujud dan emanasi dalam pandangan ibnu arabi 
Pemikiran al-Farabi tentang teori penciptaan alam semesta dengan teorinya emansi. Yaitu bahwa adanya makhluk (baharu,mumkin al wujud) adalah pancaran dari yang wajib al wujud. Artinya semua makhluk adanya karena sebab tapi sebab itu akan berakhir pada wajibul wujud (Tuhan). Pendapat Farabi ini pada dasarnya antithesis dari pendapat Plotinus yang menyatakan bahwa alam semesta ini diciptakan ex-nihilo (dari tiada) ${ }^{12}$. Dengan begitu seoalah-olahpenciptaan alam semesta oleh dua hal yang tercipta satu sama lain. Farabi menolak faham ini. Baginya apabila esensi ciptaan lain dari esensi penciptanya maka masalah penciptaan tidak mungkin dapat diciptakan, oleh sebab itu kedua-duanya adalah sama dalam esensi tapi beda dalam aktus.

Sebagaimana telah diisyaratkan, orang-orang muslim berkenalan dengan ajaran aristoteles dalam bentuknya yang telah ditafsirkan dan diolah orang-orang syiria, dan itu berarti masuk unsur-unsur Neoplatonisme. Maka cukup menarik bahwa sementara orang-orang muslim begitu sadar tentang aristoteles dan apa yang mereka anggap sebagai ajarannya, namun meraka tidak sadar, atau sedikit sekali pengetahuan adanya unsur-unsur Neoplatonisme. Hal ini menyebabkan sulit membedakan antara kedua unsur hilinisme yang paling berpengaruh kedalam filfasat islam, karena memang saling terkait. Sehingga kelak muncul dalam dunia islam paham tasawuf. Meskipun demikian para pemikir Muslim berpandangan bahwa wahyu adalah sumber ilmu pengetahuan dan karena itu mereka juga membangun berbagai teori tentang kenabian tak terkecuali al-Farabi.

\section{KESIMPULAN}

1. Bagaimanapun hasil pemikiran seseorang,amaka tidak akan terlepas dari latar belakang kehidupan dan pendidikan. Al-Farabi miliki pola berfikir logika yang diakui sebagai guru kedua setelah Aristoteles,karena beliau hidup dilingkungan dimana pemikiran filsafat Yunani sudah menjadi tradisi.

2. Dengan teori emansasi, Farabi menyimpulkan bahwa adanya alam semesta pasti ada sebab. Dan sebab itu akan berakhir pada sesuatu yang tidak bersebab. Dengan bahasa yang sederhana semua yang makhluk adalah ciptaan Allah SWT. Tapi secara teori esensi makhluk dan Allah adalah sama karena mahluk bersumber darinya. Pendapat ini merupakan bantahan dari filsafat Plotinus yang menyatakana bahwa alam semesta diciptakan dari ketiadaan.

3. Teori emansasi (Pancaran) menjadi dasar pemikiran al-Farabi dalam masalah-malah yang tidak hanya metafisika tapi juga masalah fisika (alam). Sehingga al-Farabi pada akhir hayatnya menjadi sufi yang rasional. 
4. Semua pemikir muslim dipengaruhi oleh filsafat Yunani atau Hellenisme,akan tetapi mereka tetap menghargai al-Qur'an sebagai sumber ilmu pengetahuan. Dan pola piker dalam filsafat nantinya sangat membantu dalam perkembangan ilmu kalam.

\section{DAFTAR PUSTAKA}

Oemar Amin Hoesin. Filsafat Islam, Bulan Bintang. Jakarta, 1975

Thawil Akhyar Dasoeki, sebuah komplikasi Filsafat Islam, Dina Utama, Semarang,1993

Ahmad Hanafi,MA, pengantar Filsafat Islam, Bulan Bintang. Jakarta, 1990

Ahmad Fuad Al-ahwali, Filsafat islam. Pustaka Firdaus, Jakarta, 1997

Muchtar Effendi,SE, Insiklopedi Agama dan Filsafat, Universitas Sriwijaya, 2001

Dewan Editor, Insicklopedi Tematis Dunia Islam Pemikiran dan Peradaban, Icthiar Baru Van Hoenven 